\title{
Elevated Expression of the Tyrosine Phosphatase SHP-1 Defines a Subset of High-Grade Breast Tumors
}

\author{
Luigi Insabato $^{a}$ Ivano Amelio $^{d}$ Maria Quarto ${ }^{b}$ Antonella Zannetti ${ }^{\mathrm{e}}$ \\ Fabio Tolino $^{d}$ Gaia de Mauro $^{d}$ Laura Cerchiad ${ }^{d}$ Patrizia Riccioc \\ Daniel Baumhoer ${ }^{f} \quad$ Gerolama Condorelli $^{c}$ Luigi Terracciano ${ }^{f}$ \\ Vittorio de Franciscis ${ }^{d}$
}

${ }^{a}$ Biomorphological and Functional Science, Anatomic Pathology Section, Faculty of Medicine, ${ }^{b}$ Dipartimento Scienze Fisiche, 'Dipartimento di Biologia e Patologia Cellulare e Molecolare, Università degli Studi di Napoli Federico II, ${ }^{\mathrm{d}}$ Istituto di Endocrinologia ed Oncologia Sperimentale, e ${ }^{\mathrm{e}}$ Istituto di Biostrutture e Bioimmagini, CNR,

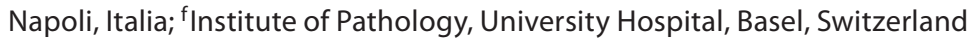

\section{Key Words}

Breast cancer $\cdot$ Tissue microarray $\cdot$ Tyrosine phosphatase $\cdot$

Clinical setting $\cdot$ SHP-1

\begin{abstract}
Objectives: Protein tyrosine phosphatases are key regulators of intracellular signaling that contribute to determining cancer cell growth, which thus makes them attractive targets for therapeutic and diagnostic agents. SHP-1 phosphotyrosine phosphatase is rarely expressed in epithelial tumor cells, but expression has been found in several breast cancer cell lines and tumors. To determine the potential significance of SHP-1 as a prognostic marker in the clinical setting, we examined SHP-1 protein expression in breast tumors. Methods: We analyzed SHP-1 expression by immunohistochemistry in a breast tissue microarray composed of 2,081 cores, either alone or in combination with known prognostic markers. Results: Our data showed that SHP-1 expression was confined to a well-defined subset of high-grade tumors characterized by unique biological parameters. SHP-1 expression correlated directly with expression of the tyrosine kinase receptor HER-2 and inversely with expression of the
\end{abstract}

\section{KARGER}

Fax +41613061234 E-Mail karger@karger.ch www.karger.com
(C) 2010 S. Karger AG, Basel

$0030-2414 / 09 / 0776-0378 \$ 26.00 / 0$

Accessible online at:

www.karger.com/ocl estrogen receptor, while it was weakly associated with $\mathrm{Bcl}-2$ expression. Conclusions: Levels of SHP-1 were correlated with conventional pathologic parameters of tumor aggressiveness and were associated with reduced patient survival, suggesting that elevated expression of SHP-1 is a common molecular abnormality in a defined subset of breast tumors and might be used in routine diagnosis to identify patients with high-risk tumors.

Copyright $\odot 2010$ S. Karger AG, Basel

\section{Introduction}

Tyrosine phosphorylation through the concerted action of protein tyrosine kinases and protein tyrosine phosphatases (PTPs) regulates the activity of key proteins involved in cell proliferation, differentiation and the cell cycle. Consequently, aberrant activation of protein tyrosine kinases by somatic mutation, amplification and/or overexpression is a frequent event in human tumors. In-

\section{L.I., I.A. and M.Q. contributed equally to this work.}

Vittorio de Franciscis

Istituto di Endocrinologia ed Oncologia Sperimentale del CNR

Via S. Pansini 5

IT-80131 Naples (Italy)

Tel. +39 0817462 036, Fax +39 0817463 308,E-Mail defranci@ unina.it 
creased tyrosine phosphatase activity has been implicated in human breast cancer and is regarded as an important diagnostic parameter [1]. PTPs do not merely attenuate kinase signaling but may directly determine cancer cell growth, which thus makes them interesting targets for therapeutic and diagnostic agents. A paradigmatic example is the SH2-containing tyrosine phosphatase SHP-2, which is implicated in various solid cancers and is found to be mutated in several leukemias [2,3]. SHP-2 and its homolog, SHP-1, are non-transmembrane phosphotyrosine phosphatases that play a key role in regulating cytokine/protein tyrosine kinase-mediated signaling and are counted among the molecular determinants that regulate cell proliferation in normal and neoplastic cells [3-6]. SHP-1 (previously named SHPTP1, HCP or PTP1C) is predominantly expressed in hematopoietic cells and likely serves as a negative regulator of most hematopoieticspecific signaling systems [7-12]. In tumors of epithelial origin, little is known about the expression of SHP-1 [13, 14]. However, the presence of high levels of SHP-1 mRNA in some breast cancer cell lines and primary breast tumors [13] suggests an active function for SHP-1 in these tumors. On the other hand, in the human breast cancer cell line MCF-7, a role for SHP-1 as a positive regulator of cell death has been suggested. Indeed, the resistance of MCF-7 cells to trichostatin A-induced apoptosis is decreased by stable overexpression of SHP-1, likely by a mechanism that involves the phosphatidylinositol 3-kinase pathway [15]. A function of SHP-1 as a positive regulator of cell death is further supported by the finding that it may act as a TrkA phosphatase, balancing the level of TrkA-induced cell survival in cultured neurons and PC12 cells [16].

To evaluate the prognostic role of SHP-1 in breast cancer, we analyzed SHP-1 protein expression in the clinical setting, using a large number of breast tumors in tissue microarray (TMA) format. TMA data were compared with molecular features, demonstrating that SHP-1, which is not expressed in normal breast tissues, is consistently present in a subset of high-grade breast cancer. High expression levels of SHP-1 correlate significantly with tumor aggressiveness, indicating that SHP-1 protein might help to make a more accurate prediction of progression of the disease.

\section{Materials and Methods}

Breast Cancer TMA and Immunohistochemistry

Four-micrometer-thick sections of TMA blocks were transferred to an adhesive-coated slide system (Instrumedics Inc., Hackensack, N.J., USA) supporting the cohesion of 0.6-mm array elements on glass. Standard indirect immunoperoxidase procedures were used for immunohistochemistry. After pretreatment with proteinase $\mathrm{K}$ (Dako, Carpinteria, Calif., USA), the anti-SHP1 antibody (ab2020; Abcam plc, Cambridge, UK) was used at a dilution of 1:500. A diaminobenzidine chromogen was used. $\mathrm{Nu}-$ clei were counterstained with hematoxylin. The percentage of positive neoplastic cells was estimated. For SHP-1, we arbitrarily used $20 \%$ as a cutoff of positivity for the purpose of statistical analysis. The scoring was performed by a single pathologist (L.I.). All slides from all tumors were reviewed by 1 of 2 pathologists to define the histologic grade according to Elston and Ellis [17] and the histologic tumor type.

Cells and Culture Conditions

MCF-7 and MCF-7 siRNA-SHP-1 cell lines were grown in DMEM (Invitrogen Corporation, San Diego, Calif., USA) supplemented with 5\% fetal bovine serum (Invitrogen), $2 \mathrm{~mm}$ L-glutamine, $1 \%$ penicillin/streptomycin, $3.75 \mathrm{ng} / \mathrm{ml}$ epidermal growth factor (Sigma, St. Louis, Mo., USA), $10 \mu \mathrm{g} / \mathrm{ml}$ insulin and $500 \mathrm{ng} /$ $\mathrm{ml}$ hydrocortisone. T47D and MDA-MB-231 cell lines were grown in RPMI-1640 (Invitrogen) supplemented with 10\% fetal bovine serum, $2 \mathrm{mM}$ L-glutamine and $1 \%$ penicillin/streptomycin. The SKBr-3 cell line was grown in DMEM supplemented with $10 \%$ fetal bovine serum, $2 \mathrm{mM} \mathrm{L-glutamine}$ and $1 \%$ penicillin/streptomycin.

MCF-7 siRNA-SHP-1 is an MCF-7 derivative cell clone stably expressing the shRNA for SHP-1 as an insert into pcDNA 6.2$\mathrm{GW} / \mathrm{miR}$ (Invitrogen). The sequence of the siRNA that specifically knocks down expression of human SHP-1 is as follows: $5^{\prime}$ TACTCCACCAGCTCTGTCAGA-3'. This sequence is followed by 19 nucleotides derived from miR-155 to form a terminal loop and sense target sequence nucleotides 1-8 and 11-21 (nucleotides 9 and 10 are removed to form a short internal loop in the mature miRNA, which results in more efficient knockdown). MCF-7 siRNA- SHP-1 cells stably expressing miRNA were established by selection with medium containing $5 \mathrm{ng} / \mathrm{ml}$ blasticidin $\mathrm{S} \mathrm{HCl}$ (Invitrogen). The medium was renewed every 3 days. After 2 weeks, resistant colonies were trypsinized, isolated and characterized.

\section{Synchronization and Cell Cycle Analysis}

Cells were rendered quiescent by serum deprivation for $24 \mathrm{~h}$ and then stimulated to re-enter the cell cycle by the addition of $10 \%$ serum. When $70-80 \%$ confluence was reached, cells were detached with trypsin and fixed with methanol overnight. Samples were resuspended in $0.5 \mathrm{ml}$ of PBS and stained with propidium iodide in the dark for $30 \mathrm{~min}$, and the DNA content was measured by fluorescence-activated cell sorting on a Becton-Dickinson FACScan flow cytometry system. The data were analyzed using Mod-FIT software.

Protein Isolation from Human Breast Tissues

Breast tissue specimens were collected from surgical mastectomy of 25 patients affected by human breast cancer. All of our studies were carried out after fulfilling all the required ethical standards of the responsible institution (Committee on Human Experimentation). Tissues were minced with a mortar and pestle (Morgan Technical Ceramics, Waldkraiburg, Germany) and then homogenized in $1 \mathrm{ml}$ of harvest buffer [50 mM Tris- $\mathrm{HCl}$ ( $\mathrm{pH} 7.4)$, $150 \mathrm{~mm} \mathrm{NaCl}, 5 \mathrm{~mm}$ EDTA, $1 \mathrm{~mm}$ sodium orthovanadate, $1 \%$ Nonidet P40 (Sigma)] containing protease inhibitor cocktail 
Fig. 1. SHP-1 protein expression in human breast tissues. a SHP-1 expression levels were analyzed by immunoblot with antiSHP-1 antibody in different breast tumors (T) or adjacent normal tissue $(\mathrm{N})$ obtained from 4 patients $(\mathrm{Pt})$. Equal loading of protein was confirmed using anti- $\beta$-actin antibody. b, c Immunoperoxidase staining for SHP-1. b Representative TMA with negative and positive cores for SHP-1. Original magnification $\times 40$. c High-grade breast carcinoma with strongly positive tumor cells. Mitotic activity is evident (arrow). Original magnification $\times 400$.
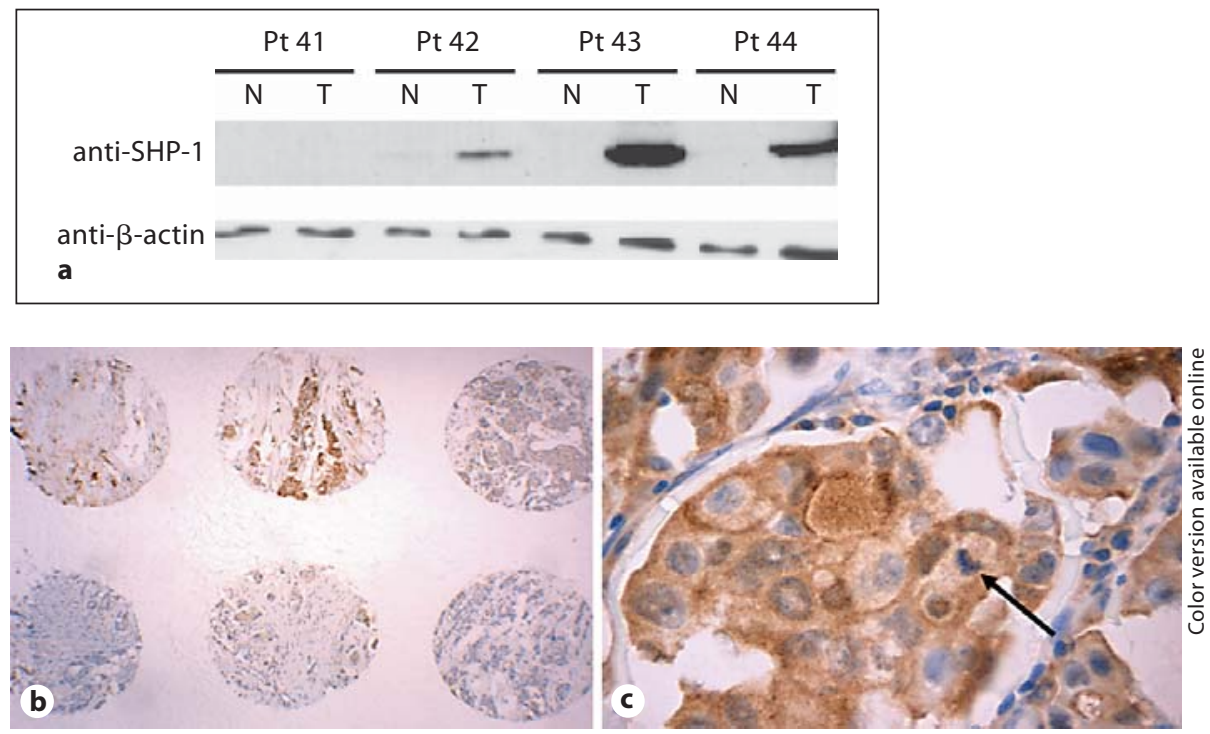

(Roche Diagnostic, Montreal, Canada), with a Dounce tissue grinder (Wheaton, Millville, N.J., USA). Solubilized proteins were incubated for $30 \mathrm{~min}$ on ice. After centrifugation at $10000 \mathrm{~g}$ for $30 \mathrm{~min}$ at $4^{\circ} \mathrm{C}$, supernatants were collected.

\section{Immunoblot Analysis}

Protein concentrations from tissues (100-200 mg each) or cell extracts were determined by Bradford assay using bovine serum albumin as standard. Thirty micrograms of each sample of protein extracts were prepared in Laemmli sample buffer, denatured for $5 \mathrm{~min}$ at $100^{\circ} \mathrm{C}$, then subjected to SDS-PAGE. Gels were electroblotted into polyvinylidene difluoride membranes (Millipore Co., Bedford, Mass., USA), and the signals were detected with the indicated primary antibodies and peroxidase-conjugated secondary antibodies using an enhanced chemiluminescence system (Amersham-Pharmacia Biosciences Ltd.). Primary antibodies used were anti-SHP-1 (C-19; Santa Cruz Biotechnology, Santa Cruz, Calif., USA) and anti- $\beta$-actin (Sigma). Secondary antibodies used were anti-mouse (Amersham-Pharmacia Biosciences) and anti-rabbit (Santa Cruz Biotechnology).

\section{$\left[{ }^{3} \mathrm{H}\right]$ Thymidine Incorporation Assay}

The plasmids pCEFL-hemagglutinin (HA), pCEFL-HA SHP1(wildtype) and pCEFL-HA SHP-1 Cys453 to Ser mutant (C/S), containing the SHP-1 gene, fused to the HA epitope. The mutated human SHP-1 (C/S) is still able to bind substrates, but it is catalytically inactive. Transient transfections ( $15 \mu \mathrm{g}$ of each plasmid) were carried out in $100-\mathrm{mm}$ cell culture dishes with Lipofectamine 2000 reagent (Life Technologies Inc.), and cells were grown in the absence of serum for $5 \mathrm{~h}$. After $16 \mathrm{~h}, 50,000$ cells were replated in triplicate in 24-well tissue culture dishes. For each transfection, a cell aliquot was lysed and protein was analyzed by immunoblot with anti-HA antibodies; equal transfection efficiency was confirmed (not shown). Six, 30 and $54 \mathrm{~h}$ after replating, cells were treated with 4 -hour pulses of $1 \mu \mathrm{Ci} / \mathrm{ml}\left[{ }^{3} \mathrm{H}\right]$ thymidine $(45 \mathrm{Ci} /$ $\mathrm{mmol}$; Amersham-Pharmacia Biosciences) added in complete growth medium and incubated at $37^{\circ} \mathrm{C}$. At the end of each pulse, dishes were placed on ice, and cells were washed with ice-cold PBS, 5\% trichloroacetic acid and, finally, with methanol. Cells were then dissolved in $0.3 \mathrm{~N} \mathrm{NaOH}$, and $\left[{ }^{3} \mathrm{H}\right]$ thymidine incorporation was analyzed by a Beckman LS 1701 Liquid Scintillation Counter.

\section{Statistics}

The associations of some molecular features with SHP-1 expression were evaluated using the $\chi^{2}$ test. To investigate the effect of high expression of SHP-1 on patient prognosis, we performed a univariate survival analysis using the Kaplan-Meier method and a log-rank test. Statistical analysis was performed using Stata software (Stata Corp., College Station, Tex., USA).

\section{Results}

\section{SHP-1 Expression in Human Breast Tumors}

We first determined the expression levels of SHP-1 in human breast cancer specimens from 4 patients for whom the corresponding adjacent normal tissue was available. None of the patients were receiving medical treatment at the time of the operation. Immunoblot analysis showed that SHP-1 was never expressed in normal breast, while it was expressed at various intensities in the adjacent breast tumor samples from 3 patients (fig. 1a).

We then analyzed the frequency of SHP-1 expression in breast tumors by using a breast cancer TMA composed of 2,081 samples (2,048 tumors and 33 normal breast controls) [18]. The large majority of tumors belonged to the ductal (1,426 cores) and lobular carcinoma (297 cores) histotypes. In line with the results obtained by immunoblot, all epithelial cells from normal breast controls were 
Table 1. Staining levels of SHP-1 in the different breast cancer histotypes of the TMA

\begin{tabular}{lrrr}
\hline Tumor histotype & \multicolumn{2}{c}{ SHP-1 staining } & Total \\
\cline { 2 - 4 } & negative & positive & \\
\hline Adenocystic carcinoma & 1 & 0 & 1 \\
Apocrine carcinoma & 13 & 1 & 14 \\
Atypical medullary carcinoma & 8 & 1 & 9 \\
Carcinosarcoma & 2 & 0 & 2 \\
Clear cell carcinoma & 8 & 4 & 12 \\
Cribriform carcinoma & 58 & 2 & 60 \\
Ductal carcinoma & 1,307 & 119 & 1,426 \\
Histocytic carcinoma & 2 & 0 & 2 \\
Lipid-rich carcinoma & 1 & 1 & 2 \\
Lipid-rich or histioc & 2 & 0 & 2 \\
Lobular carcinoma & 291 & 6 & 297 \\
Medullary carcinoma & 53 & 2 & 55 \\
Metaplastic carcinoma & 5 & 0 & 5 \\
Mucinous carcinoma & 65 & 2 & 67 \\
Neuroendocrine carcinoma & 1 & 1 & 2 \\
Papillary carcinoma & 23 & 4 & 27 \\
Signet ring carcinoma & 0 & 1 & 1 \\
Small cell carcinoma & 2 & 0 & 2 \\
Lobular carcinoma & 47 & 5 & 52 \\
Ductal carcinoma in situ & 9 & 0 & 9 \\
Lobular carcinoma in situ & 1 & 0 & 1 \\
Total & 1,932 & 149 & 2,081 \\
\hline Normal breast & 33 & 0 & 33 \\
\hline
\end{tabular}

Results for negative and positive SHP-1 expression were obtained by grouping negative and positive SHP-1 staining as described in Materials and Methods.

immunohistochemically negative for SHP-1, while a group of tumors showed cytoplasmic positivity (table 1).

Since nuclear SHP-1 staining was observed in only a small fraction of the SHP-1-positive samples (2.2\%), only cytoplasmic staining was considered positive in this setting (fig. 1b). Overall, approximately $7.2 \%$ of all breast tumors analyzed showed positive staining for SHP-1. The ductal histotype, which constituted $68 \%$ of the TMA, had a similar distribution (8.3\% of cores positive for SHP-1), while SHP-1-positive staining in the lobular carcinoma cores was much rarer, with only $2.0 \%$ of such tumors expressing SHP-1 (table 1), thus suggesting that SHP-1 expression is not homogenously distributed among all types of breast cancers.

\section{SHP-1 Defines a Subset of High-Grade Breast Cancers}

In order to test the significance of SHP-1 expression in determining the biological behavior of the disease, we
Table 2. Association between staining of SHP-1 and 3 clinical parameters: tumor grade, HER-2 overexpression and ER status

\begin{tabular}{llrrl}
\hline & & \multicolumn{2}{c}{ SHP-1 staining } & p value \\
\cline { 3 - 4 } & & total, $\mathrm{n}$ & positive, \% & \\
\hline \multirow{2}{*}{ Tumor grade } & G1 & 532 & 5 & $<0.001$ \\
& G2 & 866 & 6 & \\
& G3 & 667 & 11 & $<0.001$ \\
HER-2 & $0+1$ & 1,637 & 6 & \\
& 2 & 61 & 11 & $<0.001$ \\
& 3 & 197 & 18 & \\
\hline ER & negative & 438 & 13 & \\
& positive & 1,480 & 5 & \\
\hline
\end{tabular}

For each parameter (tumor grade, HER-2 staining intensity and ER status), the total number of tumors and the percentage of tumors that stained positive for SHP-1 are indicated. The $\mathrm{p}$ values were calculated with Stata software.

analyzed the relationship between SHP-1 expression and 3 common parameters of aggressiveness, i.e. histological grade [17] and expression levels of the HER-2 gene and the estrogen receptor (ER). As shown in table 2, $11 \%$ of high-grade tumors (G3) expressed SHP-1, while only $5 \%$ of low-grade tumors (G1) were positive for this phosphatase. In addition, $18 \%$ of the tumors that expressed high levels of HER-2 also expressed SHP-1. Accordingly, SHP1 was expressed in $13 \%$ of tumors characterized by the absence of a functional ER (ER-negative tumors).

Furthermore, by introducing a cutoff to exclude values less than $10 \%$, we tested the correlation between SHP-1 expression and the Ki67 labeling index, a marker of cell proliferation that was recently analyzed on the same TMA [18]. The Ki67 labeling index was shown to be strongly associated with high-grade tumors and was strongly linked to poor prognosis in this same cohort [18]. Here, we found that, although expression of SHP-1 correlates with molecular indicators of aggressiveness (see above), it did not correlate with high Ki67 (not shown). Taken together, these results indicate that high expression of SHP-1 identifies a subset of high-grade breast tumors, as assessed by independent parameters.

High Levels of SHP-1 Expression Are Associated with the Absence of Bcl-2 and the Presence of p16/Ink4a.

In order to further characterize tumors expressing high levels of SHP-1, we analyzed expression levels of 2 key proteins involved in cell survival and proliferation, 
Table 3. Association between SHP-1-positive tumors and Bcl-2 or p16 expression in TMA samples

\begin{tabular}{|c|c|c|c|c|}
\hline & & \multicolumn{2}{|c|}{ SHP-1 staining } & \multirow[b]{2}{*}{$\mathrm{p}$ value } \\
\hline & & total, $\mathrm{n}$ & $\begin{array}{l}\text { positive, } \\
\%\end{array}$ & \\
\hline Bcl-2 & $\begin{array}{l}0+1 \\
2+3\end{array}$ & $\begin{array}{r}311 \\
1,551\end{array}$ & $\begin{array}{r}12 \\
7\end{array}$ & $<0.01$ \\
\hline p16 & $\begin{array}{l}\text { negative } \\
\text { positive }\end{array}$ & $\begin{array}{r}1,235 \\
634\end{array}$ & $\begin{array}{r}6 \\
10\end{array}$ & $<0.001$ \\
\hline
\end{tabular}

For each parameter (Bcl-2 and p16 expression intensity), the total number of tumors and the percentage of tumors that stained positive for SHP-1 are indicated. The $\mathrm{p}$ values were calculated with Stata software.

i.e. Bcl-2, which is involved both in counteracting apoptosis and cell cycle control [19], and the tumor suppressor gene, p16/Ink4a, which acts by inhibiting the phosphorylation of retinoblastoma protein family members [20]. As shown in table 3, expression of SHP-1 was significantly higher in tumors with absent or low Bcl-2 expression $(\mathrm{p}=0.01)$ and in tumors expressing $\mathrm{p} 16 /$ Ink4a $(\mathrm{p}=$ $0.001)$.

\section{Survival Analysis}

We further analyzed the relationship between high expression of SHP-1 and patient survival. As expected, survival estimates in the whole TMA (fig. 2a) decreased with increasing tumor grade, with a value of $50 \%$ for overall survival at approximately 86 months for high-grade tumors ( $p$ value $=0.05$ ). Values and trends for survival of patients with tumors positive for SHP-1 staining (fig. 2b; $\mathrm{p}$ value $=0.022)$ were similar to those of high-grade tumors, reaching a value of $50 \%$ for overall survival at 100 months, with a similarly shaped curve, while the control population (tumors negative for SHP-1 staining) reached $50 \%$ survival at 145 months. A similar trend for survival was obtained if only the ductal histotype was analyzed, as expected with the high frequency of this tumor type in the TMA (data not shown).

\section{Expression of SHP-1 Does Not Promote Cell Proliferation}

Given the lack of correlation of SHP-1 levels with the Ki67 labeling index as a measure of cell proliferation (see above), we determined the ability of SHP-1 to promote DNA synthesis in breast cancer-derived stable cell lines.
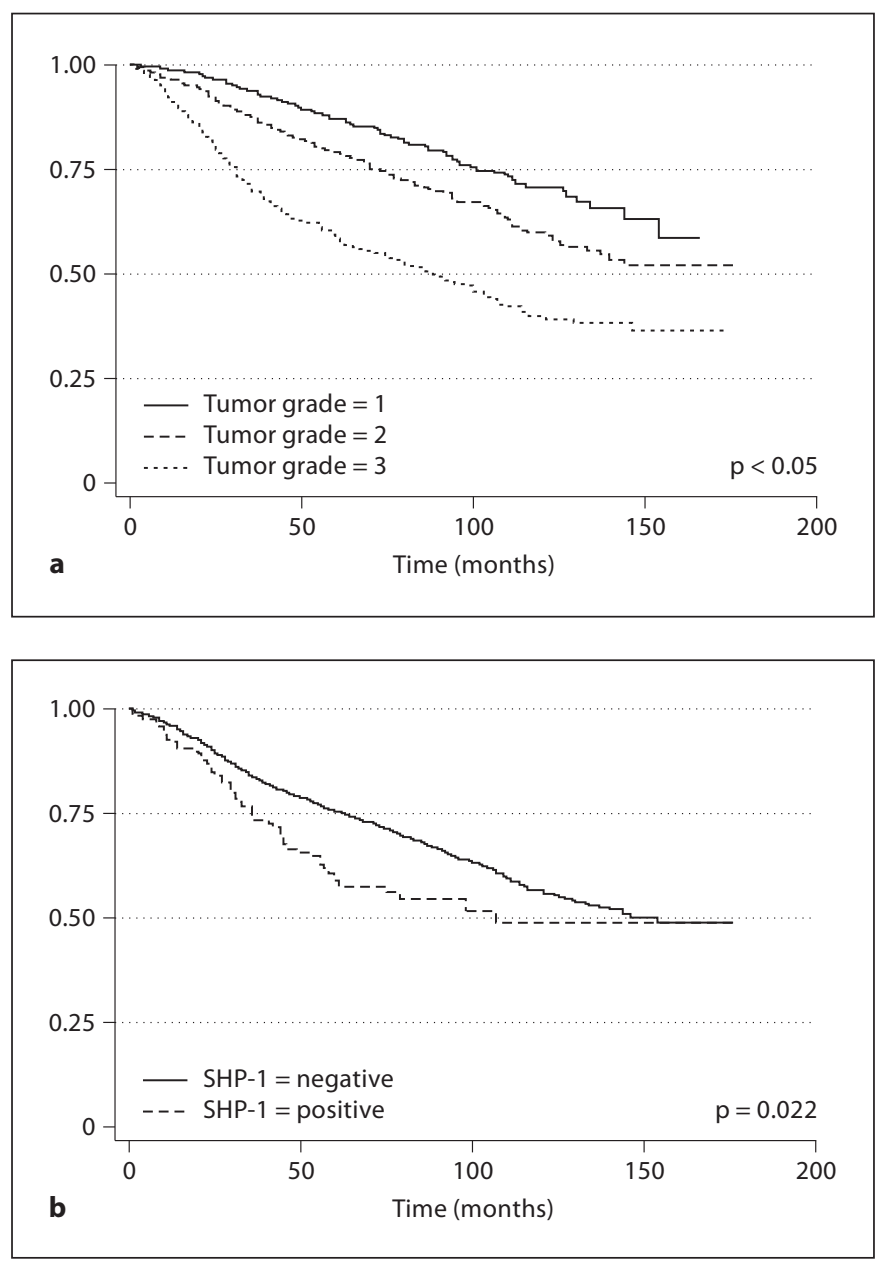

Fig. 2. Survival analysis. Survival analysis of the TMA cohort, showing Kaplan-Meier curves according to tumor grade (a) and SHP-1 expression (b).

SHP-1 was expressed in only 2 of the 4 cell lines analyzed, i.e. MCF-7 and SKBr-3, whilst T47D and MDA-MB-231 were negative (fig. $3 \mathrm{a}$ ).

As shown in figure $3 \mathrm{~b}$, forced expression of SHP-1 (wildtype) in SHP-1-negative T47D cells had low inhibitory effects on thymidine incorporation (of less than $10 \%$ at $54 \mathrm{~h}$ ), while inhibition of endogenous SHP-1 activity in MCF-7 cells by expression of the interfering mutant SHP$1(\mathrm{C} / \mathrm{S})$ had no effect (fig. 3c). Likewise, using an MCF-7 derivative cell line (MCF-7 siRNA-SHP-1) in which the expression of SHP-1 is reduced by stable expression of a specific siRNA (not shown), the percentage of cells in $S$ phase increased by around 5\% (fig. 3d). These data indicate that SHP-1 is unlikely to be functionally involved in determining the proliferation rate of those tumors in which it is expressed. 

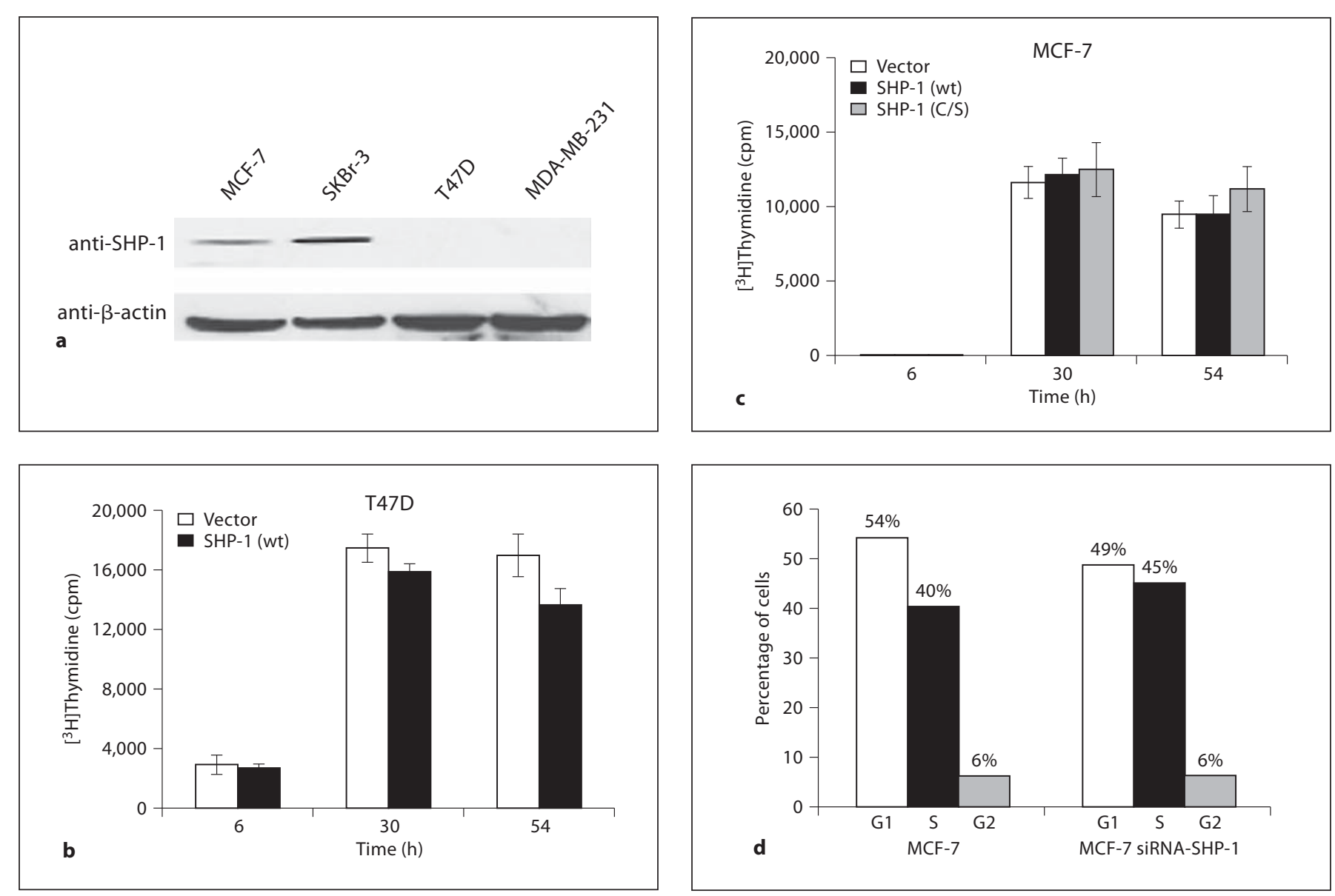

Fig. 3. SHP-1 expression does not affect thymidine incorporation in breast cancer cell lines. a SHP-1 expression levels were analyzed by immunoblot with an anti-SHP-1 antibody in exponentially growing MCF-7, SKBr-3, T47D and MDA-MB-231 breast carcinoma cell lines. Equal loading of samples was confirmed on the same blots with anti- $\beta$-actin antibody. $\mathbf{b}$ T47D cells were transfected with the vector pCEFL-HA and with pCEFL-HA SHP1 (wildtype; $w \mathrm{t}$ ), and $\left[{ }^{3} \mathrm{H}\right]$ thymidine incorporation was monitored (as described in Materials and Methods) at the indicated times. c MCF7 cells were transfected with pCEFL-HA SHP-1 (wildtype; wt) and with pCEFL-HA SHP-1 C/S, and $\left[{ }^{3} \mathrm{H}\right]$ thymidine incorpo-

\section{Discussion}

In the present study, we used a TMA-based approach to investigate the expression of the tyrosine phosphatase SHP-1 in human breast cancer in association with several clinical and biological parameters. Our data demonstrate that SHP-1 protein is expressed in tumors whilst it is absent in normal breast tissue, indicating that SHP-1 expression is frequently deregulated in breast tumors. They further indicate that high expression of SHP-1 iden-

ration was monitored at the indicated times. Values are the means of triplicate reactions, with vertical bars representing the SD. d MCF-7 and MCF-7 siRNA-SHP-1 cells were analyzed by optical cytofluorimetry analysis to determine the percentage of cells in the G1, S and G2 phases of the cell cycle. The coefficient of variation of the peaks, which represents the ratio of the standard deviation and average values, was measured to confirm the significance of measurements and was $4.5 \%$ for the MCF-7 cell line and $5.2 \%$ for the MCF-7 siRNA-SHP-1 cell line. Values are results of a representative experiment.

tifies a particular subset of breast tumors. Tumors expressing SHP-1 were in fact predominantly of the ductal type and were characterized by aggressive biological behavior. Accordingly, high expression of SHP-1 correlated directly with high HER-2 expression and inversely with ER expression. Importantly, high SHP-1 expression was significantly associated with reduced survival. Furthermore, by using independent measurable parameters present in our TMA records [18], we assigned SHP-1-expressing tumors to a rather homogeneous subset of high-grade 
tumors. Indeed, we show that, in contrast to the large majority of high-grade tumors in the TMA (data not shown), those expressing SHP-1 are weakly associated with high $\mathrm{Bcl}-2$ expression. Moreover, this subset is characterized by the frequent expression of the tumor suppressor gene p16/Ink4a.

Our results indicate that even though it seems unlikely that SHP-1 has a functional involvement in determining the highly malignant phenotype of tumors in which it is expressed, some of the effects that have previously been reported to be induced by SHP-1 in the breast cell line MCF-7 are reflected in the subset of high-grade breast tumors expressing SHP-1. Considering that SHP-1 generally opposes oncogenic signaling pathways [14], it is plausible that the overexpression of SHP-1 in tumors of advanced stage and poor clinical outcome may act as a compensatory and opposing mechanism to more pronounced oncogenic signaling.

Although SHP-1 seems to be implicated at the molecular level in regulating cell signals in hematopoietic cell lines, little is known about its involvement in cancer.
SHP-1 protein and mRNA levels are downregulated in various leukemia and lymphoma cell lines, but not in epithelial cell lines, including breast cancer cell lines, in which SHP-1 levels are normal or overexpressed $[13,14]$. To our knowledge, this is the first study on a large group of solid tumors demonstrating that elevated expression of SHP-1 may serve as a marker of poor prognosis for a subset of high-grade breast cancers characterized by unique biological parameters and with a poor clinical course that makes this set of tumors of interest for therapeutic approaches.

\section{Acknowledgements}

We wish to thank S. Del Vecchio for suggestions and comments. This work was partially supported by funds from: Associazione Italiana Ricerca sul Cancro (grants to L.C. and G.C.), MIUR-FIRB (RBIN04J4J7) and an EU grant from the European Molecular Imaging Laboratories Network (contract No. 503569). I.A. and F.T. were supported by the MIUR-FIRB grant.

\section{References}

1 Ottenhoff-Kalff AE, van Oirschot BA, Hennipman A, de Weger RA, Staal GE, Rijksen G: Protein tyrosine phosphatase activity as a diagnostic parameter in breast cancer. Breast Cancer Res Treat 1995;33:245-256.

2 Mohi MG, Neel BG: The role of Shp2 (PTPN11) in cancer. Curr Opin Genet Dev 2007;17:23-30.

3 Neel BG, Gu H, Pao L: The 'Shp'ing news: SH2 domain-containing tyrosine phosphatases in cell signaling. Trends Biochem Sci 2003;28:284-293

4 Wu CJ, O’Rourke DM, Feng GS, Johnson GR, Wang Q, Greene MI: The tyrosine phosphatase SHP-2 is required for mediating phosphatidylinositol 3-kinase/Akt activation by growth factors. Oncogene 2001;20:60186025.

5 Feng GS: Shp-2 tyrosine phosphatase: signaling one cell or many. Exp Cell Res 1999; 253:47-54.

6 D'Alessio A, Cerchia L, Amelio I, Incoronato M, Condorelli G, de Franciscis V: Shp-2 in PC12 cells: NGF versus EGF signalling. Cell Signal 2007;19:1193-1200.

-7 Mizuno K, Katagiri T, Hasegawa K, Ogimoto M, Yakura H: Hematopoietic cell phosphatase, SHP-1, is constitutively associated with the $\mathrm{SH} 2$ domain-containing leukocyte protein, SLP-76, in B cells. J Exp Med 1996;184: 457-463.

-8 Su L, Zhao Z, Bouchard P, Banville D, Fischer EH, Krebs EG, Shen SH: Positive effect of overexpressed protein-tyrosine phosphatase PTP1C on mitogen-activated signaling in 293 cells. J Biol Chem 1996;271:10385-10390.

-9 Tamir I, Dal Porto JM, Cambier JC: Cytoplasmic protein tyrosine phosphatases SHP1 and SHP-2: regulators of B cell signal transduction. Curr Opin Immunol 2000;12: 307-315.

10 Zhang J, Somani AK, Siminovitch KA: Roles of the SHP-1 tyrosine phosphatase in the negative regulation of cell signalling. Semin Immunol 2000;12:361-378

11 You M, Zhao Z: Positive effects of SH2 domain-containing tyrosine phosphatase SHP1 on epidermal growth factor- and interferon-gamma-stimulated activation of STAT transcription factors in HeLa cells. J Biol Chem 1997;272:23376-23381.

12 Amin HM, Hoshino K, Yang H, Lin Q, Lai R, Garcia-Manero G: Decreased expression level of SH2 domain-containing protein tyrosine phosphatase-1 (Shp1) is associated with progression of chronic myeloid leukaemia. J Pathol 2007;212:402-410.

-13 Yip SS, Crew AJ, Gee JM, Hui R, Blamey RW Robertson JF, Nicholson RI, Sutherland RL, Daly RJ: Up-regulation of the protein tyrosine phosphatase SHP-1 in human breast cancer and correlation with GRB2 expression. Int J Cancer 2000;88:363-368.

14 Wu C, Sun M, Liu L, Zhou GW: The function of the protein tyrosine phosphatase SHP-1 in cancer. Gene 2003;306:1-12.
$15 \mathrm{Xu}$ Y, Mousseau DD, Banville D, Zhao X, Shen SH: SHP-1 sensitizes MCF-7 cells to trichostatin A-induced apoptosis by modulating PI3K-dependent events. Cell Death Differ 2003;10:1213-1214.

-16 Marsh HN, Dubreuil CI, Quevedo C, Lee A, Majdan M, Walsh GS, Hausdorff S, Said FA, Zoueva O, Kozlowski M, Siminovitch K, Neel BG, Miller FD, Kaplan DR: SHP-1 negatively regulates neuronal survival by functioning as a TrkA phosphatase. J Cell Biol 2003;163:999-1010.

17 Elston CW, Ellis IO: Pathological prognostic factors in breast cancer. The value of histological grade in breast cancer: experience from a large study with long-term follow-up. Histopathology 1991;19:403-410.

$\checkmark 18$ Ruiz C, Seibt S, Al Kuraya K, Siraj AK, Mirlacher M, Schraml P, Maurer R, Spichtin H, Torhorst J, Popovska S, Simon R, Sauter G: Tissue microarrays for comparing molecular features with proliferation activity in breast cancer. Int J Cancer 2006;118:21902194.

19 Zinkel S, Gross A, Yang E: BCL2 family in DNA damage and cell cycle control. Cell Death Differ 2006;13:1351-1359.

20 Wong SC, Chan JK, Lee KC, Hsiao WL: Differential expression of p16/p21/p27 and cyclin D1/D3, and their relationships to cell proliferation, apoptosis, and tumour progression in invasive ductal carcinoma of the breast. J Pathol 2001;194:35-42. 